\title{
The pragmatic interpretation of intonation in Greek wh-questions
}

\author{
Amalia Arvaniti ${ }^{1}$, Mary Baltazani ${ }^{2}$, Stella Gryllia ${ }^{3}$ \\ ${ }^{1}$ English Language and Linguistics, University of Kent, UK \\ ${ }^{2}$ Linguistics, Philology \& Phonetics, University of Oxford, UK \& University of Ioannina, Greece \\ ${ }^{3}$ Leiden University Centre for Linguistics, Leiden University, Netherlands \\ a.arvanitiakent.ac.uk, mary.baltazani@ling-phil.ox.ac.uk, s.gryllia@hum.leidenuniv.nl
}

\begin{abstract}
We experimentally investigated the pragmatics of two melodies commonly used with Greek wh-questions, L*H L!H\%, described as the default, and $\mathrm{LH}^{*} \mathrm{~L}-\mathrm{L} \%$ considered less frequent and polite. We tested two hypotheses: (a) the !H\%ending melody is associated with information-seeking questions, while the L\%-ending melody is pragmatically more flexible and thus appropriate also for non-information-seeking wh-questions expressing bias; (b) the ! $\mathrm{H} \%$-ending melody, being more polite, is more appropriate for female talkers, all else being equal. In Experiment 1, comprehenders rated !Hending and L\%-ending versions of the same questions for politeness and appropriateness for the context in which they were heard (which favored either information-seeking or "biased" wh-questions). In Experiment 2, comprehenders heard the same questions and chose between two follow-up responses, one providing information, the other addressing the bias of the wh-question. Comprehenders rated !H\%-ending questions more appropriate than L\%-ending questions and judged the !H\%-ending questions of female talkers more polite. They also chose information-providing answers more frequently after !H\%- than L\%-ending questions, but the preference was higher for female talkers and depended on comprehender gender. The results argue in favor of a compositional view of intonational meaning which depends not only on the tune but also on context, broadly construed. Index Terms: $w h$-questions, intonation, pragmatics, gender
\end{abstract}

\section{Introduction}

We present data from two perception experiments on the intonational pragmatics of Greek wh-questions to argue that intonation requires, in addition to a description of its phonetic realization, a phonological representation which must take into consideration differences in meaning in tandem with differences in form. These results, in combination with the production study of [1] show that a phonological analysis is required to explain variation in the realization of intonation as well as differences in meaning and pragmatic interpretation.

In Greek $w h$-questions, the $w h$-word is utterance initial; thus the questions are marked both morphologically and syntactically as such, e.g., [pos se lene] what's your name? (lit. how you.acc call.3pl). In addition to the morphosyntactic information, wh-questions are marked by the use of a particular melody (this melody can be used with other constructions as well [2]; a discussion of these cases is beyond the scope of this paper). In addition to this default melody, wh-questions can sometimes be uttered with another melody and a different pragmatic interpretation ([1], [2], [3], [4]). Past reports on these differences, combined with our own assessment as native speakers, constitute the background of our experiments, which probe the pragmatic interpretation of the $w h$-questions when used with these two melodies.

\subsection{Melodies of Greek wh-questions}

Illustrations of the melody used by default with $w h$-questions are presented in Figure 1 below (based on [1]). A comparison between the two panels of Figure 1 shows that there is variation in the realization of the melody. In Figure 1a, which shows a short question, F0 starts high, reaching a peak on the stressed vowel of the wh-word [pu] "where," after which it quickly dips before a final small rise. Figure $1 \mathrm{~b}$ shows a longer question, in which F0 starts low, has a late peak that occurs on the syllable following the $w h$-word [apo 'pu] "from where"), and shows a rather extensive low F0 stretch before the final rise. Despite the obvious phonetic differences, these two contours are recognized by native speakers as instances of the same melody. Further, the variation illustrated in Figure 1 is systematic: it depends on the length of the question, the length of the $w h$-word itself, and the position of the stressed syllables with respect to each other and the utterance edges [1]. The representation $\mathrm{L} * \mathrm{H} \mathrm{L}-! \mathrm{H} \%$ ([1], [3]), abstracts away from phonetic detail and allows us to predict systematic differences in realization, including those illustrated in Figure 1.
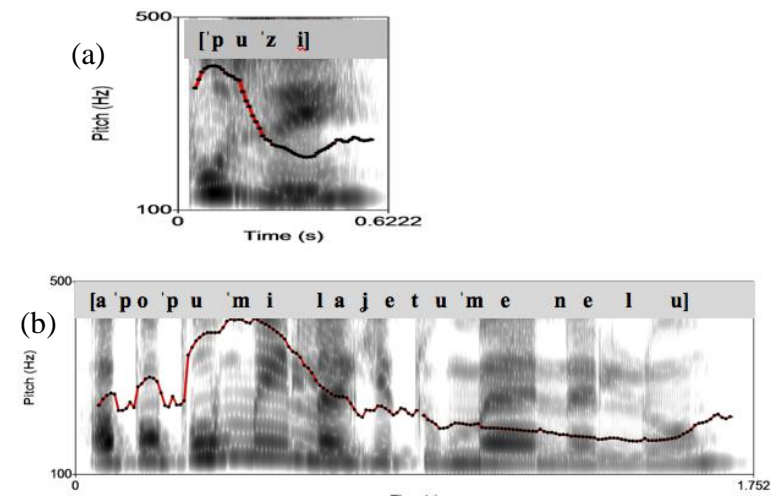

Figure 1: Spectrograms and FO contours of wh-questions:

In panel (a), ['pu 'zi] "where does he live?"; in panel (b), [apo'pu 'milaje tu 'menelu] "from where was she speaking to Menelos?". For details see text.

Although the description above covers the typical realization of contours used with wh-questions in Greek and their phonological analysis, certain issues remain unresolved. First, as noted, Greek uses an additional melody with whquestions. This has been analyzed as $\mathrm{L} * \mathrm{H}$ L-L\%, a melody similar to $\mathrm{L} * \mathrm{H} \mathrm{L}-! \mathrm{H} \%$ but ending at the bottom of the speaker's range, rather than with a final rise ([1], [3]). The fact that the two contours can be elicited under the same conditions, [1], puts into question the posited phonological difference between !H\% and L\%; !H\% could represent simply a return to a default mid-level pitch rather than a meaningful difference (cf. [6]). If so, then the difference between ! $\mathrm{H} \%$ and 
$\mathrm{L} \%$ is one of phonetic realization and as such it need not be included in the phonological representation.

As a first step in addressing this issue, we conducted an exploratory production study in which two female and two male native speakers of Greek produced sixteen questions in two types of contexts which, based on our assessment as native speakers, should lead to the use of either the $! \mathrm{H} \%$ - or the L\%-ending melody; the contexts were similar to those presented in (1a) and (1b) below.

Both our male and our female speakers produced distinct melodies in response to the different contexts suggesting that the two melodies convey different pragmatic meaning and therefore, that they are phonologically distinct. Acoustic analysis of these data indicates that the melodies differ systematically not only in the way they end but also in the pitch accent associated with the $w h$-word. The !H\%-ending melody has an accent best represented as $\mathrm{L}^{*} \mathrm{H}$ ([1], [7]), as it starts with a marked rise (Figure 2, filled symbols, solid lines), while the L\%-ending melody has an accent best represented as LH* ([3], [4], [8]), which typically starts with a peak (as its L tone is truncated when the $w h$-word is short (Figure 2, unfilled symbols, broken lines). These results support previous descriptions ([1], [3]) about a systematic difference in the way the melodies end but also establish differences in regards to the pitch accent on the $w h$-word (cf. [4]).

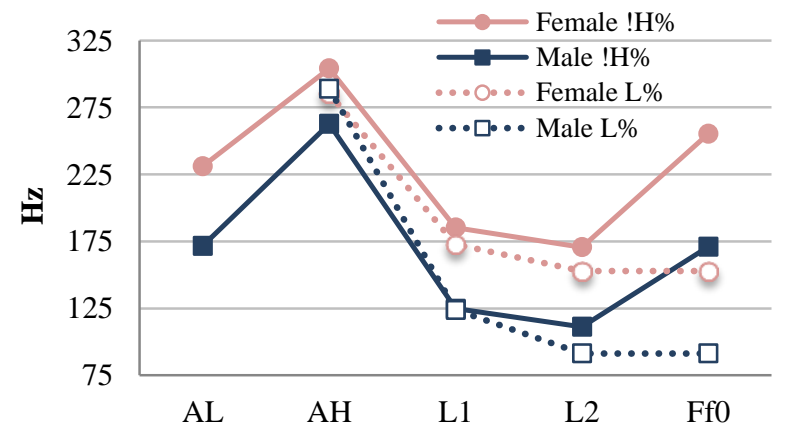

Figure 2: Average $\mathrm{FO}$ values (in $\mathrm{Hz}$ ) of the stimuli used in the two experiments, separated by gender and melody; $A L=F O$ onset; $A H=$ accentual peak; $L 1, L 2=$ beginning and end of low-FO stretch respectively; FfO = final FO value in melody. Note that $L 2$ in the L\%-ending contours is added for clarity.

Here we investigate the differences in meaning associated with these differences in realization by means of two perception experiments conceived on the basis of the production data briefly discussed above and the following observations by [1] and [3]. According to [3], L*H L-L\% sounds less polite or less "involved" than $\mathrm{L}^{*} \mathrm{H} \mathrm{L}-\mathrm{H} \%$, as if the speaker does not care for an answer; [1] note that the L\%ending tune was rare in their data (accounting for only $8 \%$ of tokens) and most instances were elicited from male talkers.

Based on the above, our hypotheses regarding the two melodies were as follows. First, the ! $\mathrm{H} \%$-ending melody is the default melody for $w h$-questions and therefore the most appropriate when questions serve their primary function of seeking information. Second, the L\%-ending melody is appropriate for both information-seeking and non-information seeking questions. Non-information-seeking questions can serve various functions; e.g. [4] discusses rhetorical questions and notes they are produced with the L\%-ending melody. Here we investigated questions indicating questioner bias for a specific answer (cf. [9]); such questions serve as an indirect way of making a statement. We hypothesized that !H\%-ending questions would be deemed inappropriate in this context, while L\%-ending questions would be highly preferred. Finally, we hypothesized that the L\%-ending melody, being less polite, would not be as appropriate for female as for male talkers, especially in requests for information [3].

\section{Exp. 1: Appropriateness and politeness}

In Experiment 1 comprehenders rated $\mathrm{LH}^{*} \mathrm{~L}-\mathrm{L} \%$ and $\mathrm{L} * \mathrm{H} \mathrm{L}-$ !H\% versions of six wh-questions for their appropriateness and politeness in a given context.

\subsection{Participants}

Eighty-nine comperhenders took part in the experiment. They provided information about their linguistic background and history on the basis of which 13 were not considered for further analysis as they turned out to be either bilingual or have a history of speech or hearing disorders. Two more comprehenders were excluded as they failed to respond to more than $20 \%$ of the trials. Results reported here are based on 74 comprehenders, 56 female and 18 male. They were all monolingual native speakers of Greek studying at the University of Ioannina, and ranged in age from 18 to 22 years.

\subsection{Stimuli}

The stimuli were six pairs of Greek wh-questions, one !H\%and one L\%-ending version per pair. The questions were selected from our corpus of 128 questions discussed in section 1.1. and were evenly divided among the four speakers of that corpus. The six pairs of questions were chosen on the basis of their naturalness. The total number of stimuli was 48 questions (6 $w$ h-questions $\times 2$ melodies $\times 4$ speakers).

We constructed two contexts for each question, so that each context in a pair would most likely lead to a different response: an information-seeking question, as in (1a) or a biased question as in (1b). Specifically, a question following a context such as (1b) would be interpreted in Greek as an attempt by the speaker not to seek information but, rather, to elicit addressee acquiescence to an indirect point (which reflects the questioner's bias for a particular answer). In our example, this indirect point is recognition on the part of the addressee that going to Syntagma would be difficult, if not impossible, under the circumstances. The contexts were read by a different native speaker of Greek. Contexts and questions were crossed for a total of 96 trials ( 48 melodies $\times 2$ contexts) so that each question was heard after (a) a context that made asking for information a plausible action or (b) a context that did not necessitate an information-seeking action.
(1a) Context: Lena, who is visiting Athens for the first time, stops a passerby for directions:
Question: ['pos $\theta$ a 'pao sto 'sidayma] 'How will I get to Syntagma?'
(1b) Context: A protest march in Syntagma is scheduled for the time Kostas has an interview there; as they listen to the news, Kostas says to his wife:
Question: ['pos $\theta$ a 'pao sto 'sidayma] 'How will I get to Syntagma?'

We expected that !H-ending questions would be rated more appropriate after contexts like (1a), while L\%-ending questions would be rated more appropriate after contexts like 
(1b). In addition we expected that in information-seeking contexts !H\%-ending questions would be rated more polite than L\%-ending questions, and that melody would interact with talker gender so that !H-ending melodies would be rated more polite if the talker was female.

\subsection{Procedures}

The comprehenders heard each context followed by a question over loudspeakers in a classroom at the University of Ioannina and filled in hard copy response sheets. They were tasked with rating how appropriate and polite each question was in the context that preceded it, using a 1-7 rating scale. The timeline of each trial is presented in Figure 3.

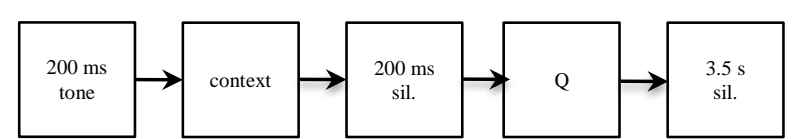

Figure 3: Timeline of a trial in Experiment 1.

\subsection{Results}

Ordinal logit regression showed that comprehenders judged questions more appropriate when they were preceded by a context that made information-seeking a plausible action $[$ Wald $=219.6, p<0.0001$; Figure 4a]. They also rated $! \mathrm{H} \%$ ending questions more appropriate than L\%-ending ones [Wald $=155, p<0.0001 ;$ Figure 4b].
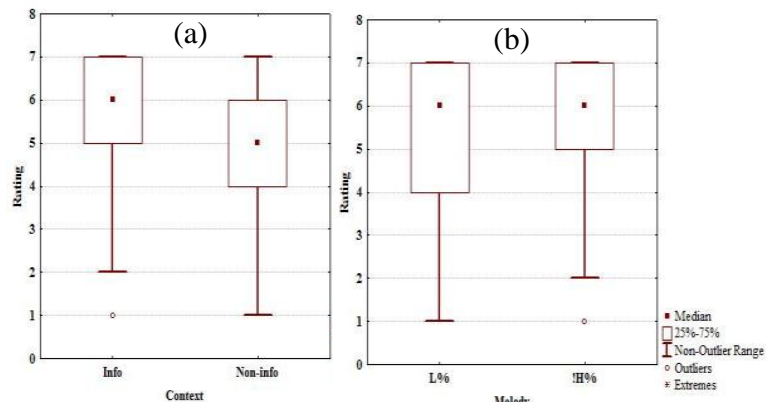

Figure 4: Appropriateness ratings as a function of context (left) and melody (right).

Regarding politeness, results showed an interaction between melody and talker gender [Wald $=15.5, p<0.0001]$. Melody did not affect the rating of questions uttered by male talkers, but it did affect questions by female talkers: their questions were judged more polite when !H\%-ending (Figure 5).
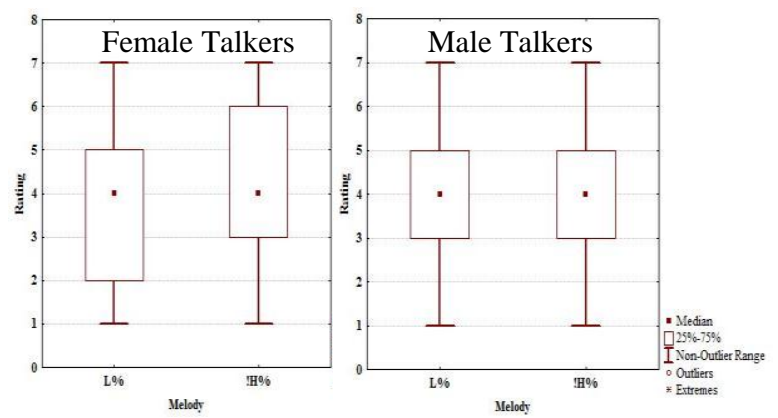

Figure 5: Politeness ratings as a function of melody, separately for female (left) and male (right) talkers.

Post-hoc analysis also showed that both appropriateness and politeness were affected by comprehender gender, with females giving overall lower politeness ratings than males [Wald $=35.5, p<0.0001]$ but higher appropriateness ratings [Wald $=52.2, p<0.0001]$.

\section{Experiment 2: Pragmatic interpretation}

\subsection{Participants and stimuli}

A different set of 79 comprehenders took part in Experiment 2. The data of six of them were discarded for the same reasons as before. The results reported here are based on 73 comprehenders (55 female and 18 males) with the same demographics as in Experiment 1 . The same ! H\%- and $\mathrm{L} \%$ ending versions of the six questions used in Experiment 1 were also used here.

\subsection{Procedures}

The questions were presented aurally out of context under the same conditions as in Experiment 1. The comprehenders' task was to choose one of two possible responses to each question, presented to them in hard copy response sheets: (i) an information-providing response or (ii) a response that agreed with the bias implied by the question. There was a total of 48 trials ( 6 wh-questions $\times 2$ melodies $\times 4$ speakers).

The setup is illustrated in (2): comprehenders heard a question like "how will I get to Syntagma?" (stimulus) and had to choose between two possible responses (counterbalanced across trials): Response A which provides information and Response B, which concurs with an implicit bias attributed to the questioner. The timeline of a trial is presented in Figure 6.

\section{(2) Stimulus: ['pos $\theta$ a 'pao sto 'sidayma]}

'How will I get to Syntagma?'

Response A: You will take line 3 and get off at (stop) Syntagma.

Response B: You're right, you can't go. There'll be mayhem.

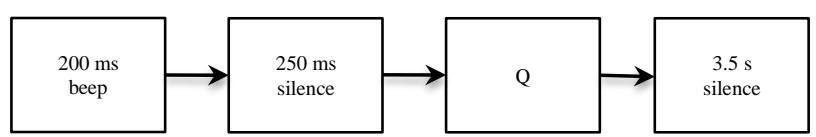

Figure 6: Timeline of a trial in Experiment 2.

It was expected that the comprehenders would be more likely to interpret !H\%-ending questions as informationseeking and thus choose an information-providing response, such as Response A in (2). On the other hand, L\%-ending questions would be more likely interpreted as indicating the questioner's bias, rather than seeking information. Thus comprehenders would be more likely to select the answer that did not provide information but concurred with this bias, such as Response B in (2).

\subsection{Results}

Logit regression showed that comprehenders preferred information-providing responses to responses concurring with (the questioner's implied) bias when questions were ! $\mathrm{H} \%$ ending [Wald $=49.1, p<0.0001]$. The preference was stronger for female than male talkers [Wald $=7.6, p<0.01$ ] Panels (a) and (b) of Figure 7 illustrate these two points respectively. 
Post-hoc analysis showed an additional effect of comprehender gender [Wald $=6.9, p<0.01]$, indicating that among comprehenders females chose information providing responses less often than males (Figure 7c). Post-hoc investigation of the interaction between comprehender and talker gender [Wald $=4.7, p<0.05$ ], illustrated in Figure 8 further indicates that the difference between male and female comprehenders was due to the fact that female comprehenders chose information providing responses less often when the talkers were male; i.e., they more frequently interpreted male than female stimuli as more likely to indicate bias rather than be genuine requests for information.
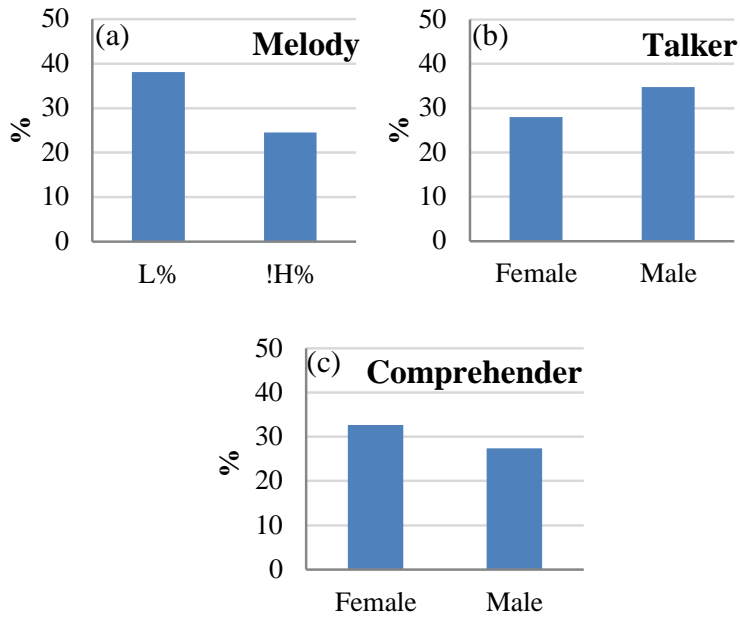

Figure 7: Percentages of bias concurring responses as a function of melody (panel a), talker gender (panel $b$ ) and comprehender gender (panel c).

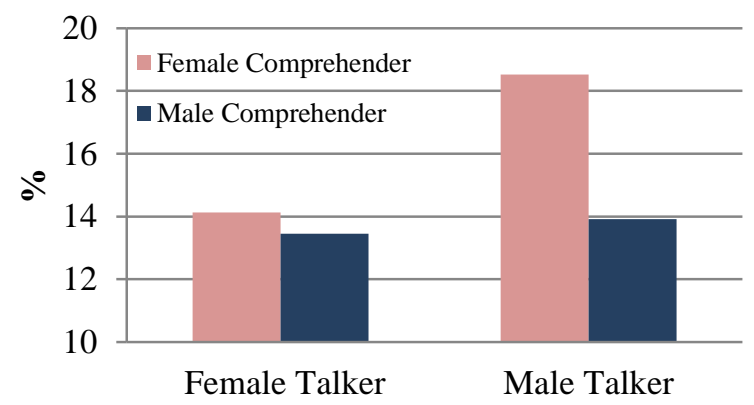

Figure 8: Percentages of bias concurring responses as a function of comprehender and talker gender.

\section{Discussion}

Our results confirmed that the two boundary tones cannot be seen as "allophonic" as each one leads to a different evaluation of the questions, in terms of their politeness and appropriateness as responses, as well as to a different interpretation of their pragmatic intent. In addition, our data showed that the assumption held in the literature, [1], [3], that the accent of the two melodies is the same must be incorrect, at least for the questions used in our experiments. Overall then, our results support the view that we are dealing with two different melodies, L*H L-!H\% and LH* L-L\% (cf. [4]).

Here we offer a preliminary compositional pragmatic analysis of the two melodies, which is based on attributing different pragmatic interpretations to the two melodic components that vary between the two tunes: the pitch accent $\left(\mathrm{L} * \mathrm{H}\right.$ or $\left.\mathrm{LH}^{*}\right)$ and the boundary tone $(! \mathrm{H} \%$ or $\mathrm{L} \%)$. Each of these components contributes to the pragmatic interpretation of the whole question.

Specifically, we maintain that the two melodies differ in givenness and completeness status: the $\mathrm{L} * \mathrm{H} \mathrm{L}-! \mathrm{H} \%$ melody is composed of a pitch accent which marks new information in Greek ([7]), and a boundary tone which marks the utterance as incomplete thereby inviting an answer ([1]; cf. [10]). The LH* L-L\% melody is composed of a pitch accent typically used to mark contrastive focus in Greek: it conveys that the accented item (and not some alternative) should be believed (cf. [8]) and marks the remainder of the utterance as given. The L\% boundary tone marks the utterance as complete ([1]; cf. [10]). The result of combining these components, $\mathrm{L} * \mathrm{H}$ with $! \mathrm{H} \%$ and $\mathrm{LH}^{*}$ with $\mathrm{L} \%$, is that while the former questions are interpreted as requiring an answer, the latter need not function as such. This in turn explains why the $\mathrm{L}^{*} \mathrm{H} \mathrm{L}-! \mathrm{H} \%$ melody is restricted to questions proper, while the $\mathrm{LH}^{*} \mathrm{~L}-\mathrm{L} \%$ melody can be used more widely.

The results are also of interest from the point of view of processing and the value of experimental research in intonational pragmatics. First, our experiments showed that the comprehenders preferred taking $w h$-questions at face value, i.e. interpreting them as requests for information. This is not surprising given that, as noted, wh-questions in Greek are morphosyntactically marked as such. It is significant however that this preference was modulated by melodic changes which shifted responses towards alternative interpretations without concomitant morphosyntactic changes. Crucially, both talker and comprehender gender played a part in the interpretation and evaluation of questions, with female comprehenders in Experiment 2 being more likely to interpret stimuli from male talkers as statements than as questions (as compared to how they treated the stimuli from female talkers). This suggests that intonational pragmatics does not depend only on the interaction of melody with semantics and linguistic context, as is often maintained, but can be affected by additional factors, such as talker and addressee gender. Thus focusing exclusively on speaker intent when examining intonational pragmatics may be unnecessarily constricting, since, clearly, all participants in a conversation play an active part in constructing intonational meaning.

\section{Conclusion}

The results confirmed $\mathrm{L} * \mathrm{H} \mathrm{L}-! \mathrm{H} \%$ as the default melody for Greek wh-questions, supporting our hypothesis about a difference in the pragmatic interpretation of the $\mathrm{L} * \mathrm{H} \mathrm{L}-! \mathrm{H} \%$ and $\mathrm{LH}^{*} \mathrm{~L}-\mathrm{L} \%$ melodies that string-identical Greek whquestions are uttered with. Since these interpretations were available to comprehenders out of context and despite the presence of a fronted $w h$-word clearly marking the stimuli as wh-questions, our findings suggest that intonation can win over conflicting morphosyntactic information. Evidence was also found that both talker and comprehender gender must be factored into the pragmatic analysis, in addition to melody, semantics and linguistic context. These results strongly suggest that acknowledging comprehender expectations about the social use of melodies is crucial for fully understanding intonational pragmatics. Finally our results show that closer attention is due to the systematic differences in meaning that relate to melodic variation. 


\section{References}

[1] Arvaniti, A. and Ladd, D. R., "Greek wh-questions and the phonology of intonation", Phonology, 26: 43-74, 2009.

[2] Baltazani, M., Quantifier Scope and the Role of Intonation in Greek. Doctoral thesis, UCLA. 2002.

[3] Arvaniti, A. and Baltazani, M., "Intonational analysis and prosodic annotation of Greek spoken corpora", in S. Jun (Ed], Prosodic Typology: The Phonology of Intonation and Phrasing, 84-117, Oxford University Press, 2005.

[4] Dimos, K., "Intonational features of Greek questions [Epitonika xaraktiristika erotimatikon protaseon tis ellinikis]". Master's thesis, Univeristy of Ioannina, Greece, 2011.

[5] Ladd, D.R., Intonational Phonology. Cambridge University Press, 2008.

[6] Grabe, E., Comparative Intonational Phonology: English and German. (MPI Series in Psycholinguistics 7), Ponsen and Looijen, 1998.

[7] Arvaniti, A., Ladd, D.R. and Mennen, I., "Stability of tonal alignment: the case of Greek prenuclear accents", Journal of Phonetics, 26: 3-25, 1998.

[8] Arvaniti, A., Ladd, D.R. and Mennen, I., "Effects of focus and 'tonal crowding' in intonation: Evidence from Greek polar questions", Speech Communication, 48: 667696, 2006.

[9] Gunlogson, C., True to Form: Rising and Falling Declaratives as Questions in English. New York: Routledge, 2003.

[10] Pierrehumbert, J. and Hirschberg, J., "The meaning of intonation in the interpretation of discourse", in P. Cohen, J. Morgan, and M. Pollack [Eds], Intentions in Communication, 271-311, MIT Press, 1990. 